\title{
INVESTIGANDO O TERMO ‘ENUNCIAÇÃO’ PARA UMA HISTÓRIA DAS IDEIAS LINGUÍSTICAS
}

\author{
INVESTIGANDO EL TÉRMINO "ENUNCIACIÓN" PARA UNA HISTORIA DE LAS IDEAS LINGÜÍSTICAS \\ INVESTIGATING THE TERM ‘ENUNCIATION’ TO A HISTORY OF LINGUISTIC IDEAS
}

\author{
Silvana Silva* \\ Universidade Federal do Pampa - UNIPAMPA, BR
}

\begin{abstract}
RESUMO: A história da linguística tem sido escrita de diversas formas. Atrelada ou não a conceitos oriundos de outras áreas, poucos estudiosos da linguística pensaram sobre seus próprios critérios de historicidade (NORMAND, 2009a). Tendo esta questão em vista, objetivamos discutir dois métodos de estudo histórico da palavra 'enunciação'subjacentes aos trabalhos de Aya Ono (2007) e Simone Delassale (1986). O primeiro trabalho explora a historicidade da palavra 'enunciação' interna à obra de um linguista. O segundo, a historicidade de 'enunciação' em fontes variadas. Procuraremos demonstrar quais as contribuições de cada trabalho para o estudo da história da linguística. Nosso procedimento metodológico parte da elaboração de noções teóricas propostas por Normand (2009a). Concluímos que o trabalho de Delesalle (1986) representa uma possibilidade de reflexão fundamental ao linguista da atualidade, pois nos conduz a pensar na figura de um narrador-linguista de uma forma 'polifônica'.

PALAVRAS-CHAVE: história da linguística; linguística da enunciação; enunciação.
\end{abstract}

RESUMEN: La historia de la lengua se ha escrito de diversas maneras. Vinculados o no a los conceptos de otras áreas, pocos estudiosos de la lingüística pensaban en sus propios criterios de historicidad (NORMAND, 2009a). Con este tema en mente, nuestro objetivo es analizar dos métodos de estudio de la historia de la palabra "enunciação'subjacentes obra de Aya Ono (2007) y Simone Delassale (1986). El primer artículo explora la historicidad de la palabra "expresión" interna a la labor del lingüista. La segunda, la historicidad de 'expresión' en varias fuentes. ¿Qué tratan de demostrar las contribuciones de cada obra al estudio de la historia de la lingüística. Nuestro enfoque metodológico parte del desarrollo de nociones teóricas propuestas por Normand (2009a). Llegamos a la conclusión de que el trabajo de Delesalle (1986) representa una oportunidad para reconsiderar el lingüista hoy en día, ya que nos lleva a pensar en la figura de un narrador-lingüista en una "polifonía".

PALABRAS CLAVE: historia de la linguística; lingüística de la enunciación; la enunciación.

ABSTRACT: The history of Linguistics has been written in various ways. Linked or not to concepts from other areas, few scholars of Linguistics thought about their own criteria of historicity (NORMAND, 2009). With this issue in mind, we aim at discussing two methods of historical study of the word 'enunciation' underlining the work of Aya Ono (2007) and Simone Delassale (1986). The first paper explores the historicity of the word 'enunciation' internal to the work of a linguist. The second, the historicity of 'enunciation' in various sources. We will try to demonstrate the contributions of each work to the study of the history of linguistics. Our methodological procedures are based on the elaboration of theoretical notions by Normand (2009a). We conclude that the work of Delesalle (1986) represents an opportunity of reflextion to the linguist at present times, because it leads us to think of the figure of a narrator-linguist in a 'polyphonic' way.

KEYWORDS: linguistics history; enunciation history; enunciation.

\section{ABORDAGENS DA LINGUÍSTICA: COMO SE TEM CONTADO ESTA HISTÓRIA?}

Professora de linguística, tenho me perguntado ultimamente sobre como ensiná-la, como abordar sua diversidade em face de curiosos mas desconfiados alunos ingressantes do Curso de Letras. 'Linguística: que bicho é esse?’ parecem me dizer seus olhos. Os livros de linguística tampouco ajudam a compor uma resposta forte, decisiva, segura. A história da linguística tem sido escrita de diversas formas: seja de forma temática ou por escolas (MUSSALIM; BENTES, 2004), por determinação de objetos de pesquisa (FIORIN, 2005), problematológica (AUROUX, 1998), por funções ou tarefas (MARTIN, 2003). Inquietou-me sobretudo o título do prefácio da obra de 'Convite à linguística', de Claudine Normand (2009b), a saber, "Sobre Saussure, Benveniste e outras histórias da linguística” assinado por Valdir Flores e Leci Barbisan. Seriam 'Saussure' e 'Benveniste’ não ‘autores' como sempre os concebi e sim 'histórias da linguística’? Logo me dou conta de que entendê-los como 'autores' os colocavam como 'senhores da História', mas como 'histórias da linguística' os conformava a ser parte de uma história contada por outros, estes sim, autores. O modo como nos contaram a Linguística ou como eu posso contá-la a nossos alunos é determinante, então,

\footnotetext{
* Doutora em Letras pela UFRGS. Email: ssilvana2011@gmail.com.
} 
não apenas da 'importância' que tais autores têm para os alunos como também da velocidade como podem esquecê-los ou lembrar deles em suas trajetórias acadêmica e profissional.

Não me interessa neste momento fazer alguma 'estatística', mas arrisco a dizer que a abordagem por escolas e a por objetos de pesquisa são as mais utilizadas nas universidades brasileiras. É comum observarmos grupos de pesquisa fechados em seus objetos com pouco diálogo com perspectivas 'vizinhas' ou mesmo fechados em suas visões teóricas.

Com o objetivo de sacudir algumas certezas sobre o fazer da linguística, proponho um estudo da palavra 'enunciação' em abordagem problematológica, isto é, em um questionamento sobre seu próprio fazer, sobre 'a' visão filosófica dominante de uma percepção ou outra. Justificamos a escolha da palavra 'enunciação', uma vez que não há no Brasil uma tradição de estudos enunciativos. Apenas recentemente, com os trabalhos de Brait (2001) e Flores e Teixeira (2005) começou-se a sistemizar o chamado 'campo enunciativo' em nosso país. Assim, o primeiro trabalho é uma coletânea de vários autores, versando sobre as obras de AuthierRevuz, Bakhtin, Greimas, Jakobson e estudiosos brasileiros da enunciação. O segundo trabalho organiza-se em torno de teorias de autores como Benveniste, Bakhtin e Bally, tendo como critério "a singularidade de leitura que fazemos do campo da enunciação" (FLORES; TEIXEIRA, 2005, p.8). De qualquer forma, não constatamos nos trabalhos referidos uma discussão sobre o que significa refletir sobre a "história da linguística’.

Para realizar o objetivo de estudar a palavra 'enunciação', analisaremos o trabalho de dois autores: Delasalle (1986) e Ono (2007). O primeiro trabalho explora a historicidade da palavra 'enunciação' interna à obra de um linguista. O segundo, a historicidade de 'enunciação' em fontes variadas. Procuraremos demonstrar quais as contribuições específicas de cada trabalho para o estudo da história da linguística, de forma geral, e para o estudo da enunciação, de forma particular.

Antes de deslindar nosso objetivo, é importante definir o que entendemos por 'abordagem problematológica'. Segundo Auroux (1998, p. 19-20):

há problemas aos quais basta aplicar um método conhecido para obter uma resposta em número finito de etapas. (...) Nem todos os problemas são dessa espécie. Para alguns, não encontramos método geral, e para outros ainda, sabemos até que não existe método geral de resolução. (...) Se conhecêssemos uma só maneira de saturar e uma só solução, não estaríamos mais na filosofia, mas no conhecimento positivo.

Compreendemos que a abordagem problematológica pode ser aquela em que apresentamos duas ou mais respostas a uma mesma questão, desde que elas surgem de pontos de vista filosóficos diferentes. Segue Auroux (1998, p. 21), "A linguística geral é livre para escolher os problemas que pretende tratar e para rejeitar outros (...) Por isso, torna-se claro que ela não poderá substituir uma filosofia da linguagem que pretenda assumir os problemas que acabamos de situar." $\mathrm{Na}$ abordagem problematológica, é possível encontrar então uma perspectiva linguística stricto sensu e uma perspectiva linguística lato sensu (histórica, filosófica, sociológica, etc.). Nosso objetivo principal é detectar a presença ou ausência dessa abordagem problematológica em duas historiadoras da enunciação: Delesalle (1986) e Ono (2007). Temos como hipótese que a segunda, mais conhecida do leitor brasileiro $^{1}$, não se vale de uma abordagem plenamente problematológica.

Da seguinte forma, refere-se Ono (2007) ao trabalho de Delesalle (1986) na primeira página da introdução do primeiro capítulo de seu livro 'La notion de enonciation chez Benveniste', intitulado 'Énonciation: le mot et la notion':

Pour Simone Delesalle, Henry Weil et Charles Bally sont les précurseurs de la linguistique énonciative [...] Se réferer à Benveniste lorsqu'on définit l'énonciation est devenu, on le sait, un pratique courante en linguistique française. En ce sens, l'article de Delesalle est répresantif à plus d'un titre. Il est d'ailleurs

\footnotetext{
${ }^{1}$ Ono (2007) fez parte da bibliografia obrigatória da disciplina de “Teorias da Enunciação”, ministrada pelo Prof. Dr. Valdir Flores no Programade Pós-Graduação em Estudos da Linguagem (UFRGS) no ano de 2009, quando cursamos essa disciplina como aluna de doutorado. A leitura de Delasalle é indicada pelo texto de Ono (2007).
} 
facile de constater cette tendance aussi bien dans les dictionnaires de langue que dans les études linguistiques. ${ }^{2}$ (ONO, 2007, p. 28).

Ono (2007) reconhece o valor histórico do trabalho de Delesalle, isto é, o de demarcar uma 'origem', uma 'verdade' histórica. Decorrem daí duas questões: 1) De que natureza é este valor histórico?; 2) Qual é ou pode ser a repercussão desse 'valor histórico’ à história da linguística, mais precisamente, à história da linguística da enunciação?

No próximo item, discutiremos os critérios de historicidade subjacentes tanto ao trabalho de Ono (2007) quanto ao trabalho de Delesalle (1986). Partiremos da discussão de tais critérios a partir de Normand, no artigo intitulado "Comment faire la histoire de la linguistique?" (1980/2009a). Escolhemos esta autora, pois, em nossa concepção, ela apresenta formação tanto em Linguística quanto em Filosofia além de apresentar profundo conhecimento de Saussure e de Benveniste. Acreditamos que as noções teóricas apresentadas pela autora - e expostas na seção 2, a seguir - nos ajudam a compor o procedimento metodológico para a compreensão da historicidade subjacente a Ono (2007) e a Delesalle (1986).

\section{HISTÓRIA DA LINGUÍSTICA, HISTÓRIAS PARA LINGUÍSTICAS OU HISTORIADOR DA LINGUÍSTICA?}

Neste item, apresentaremos uma discussão dos critérios de historicidade tal como apresentados por Normand (2009a). Refletiremos ainda sobre a pertinência e o alcance do sintagma 'história da linguística'.

Antes, no entanto, é necessário fazer uma breve reflexão sobre o que significa 'fazer história da linguística'. Colombat, Fournier e Puech (2010, p. 11) nos ajudam em tal reflexão. Inicialmente, os autores se se perguntam se fazem histórias de teorias linguísticas ou de ideias linguísticas. Afirmam que se deve pensar em 'ideias linguísticas', pois, dessa forma, tomamos um ponto de vista epistemológico menos engajado do que os teóricos e também, ao mesmo tempo, mais respeitoso com a diversidade de formas de compreender a linguagem e as línguas. Os autores se perguntam ainda: “o historiador de saberes linguísticos deve ser relativista?” (2010, p. 240). Segundo os autores, o historiador de saberes linguísticos é, certamente, relativista, pois deve definir com prudência conceitos ou teorias linguísticas ou, ao menos, delimitá-los menos estreitamente do que no período que eles se estabelecem. Perguntam: “Le moindre des risques qu’il court n'est-il pas celui de l'anachronisme et du présentisme, réduisant l'étude historique à la recherche des 'precurseurs'?"3 (2010, p. 240). Assim, tratar autores diferentes, mesmo que cronologicamente contemporâneos, como 'presentes' é tão nefasto para a história das ideias linguísticas como o de procurar uma 'linha de filiação’ única. Por isso, estando de pleno acordo com os autores, entendemos que a melhor noção para situar este artigo é a de 'histórias para linguísticas'. Com isso, queremos dizer que a melhor forma de fazer história da linguística é tentar não 'optar’ por uma única forma de teorizar, revelando as diferentes abordagens de leituras.

Normand (2009a, p. 22) observa a existência na França de dois paradigmas de elaboração de noções teóricas internas ao mesmo autor ou de leituras de um termo/conceito de um autor em relação a outro, a saber: $1^{\circ}$ ) o desenvolvimente, a maturação, os precursores, as influências, em suma, a mudança na continuidade; $2^{\circ}$ ) as rupturas, os cortes, uma revolução científica, em suma, a mudança na descontinuidade ${ }^{4}$. Segundo a autora, ambas as perspectivas se apresentam como promotoras de 'mudanças teóricas radicais'. Acrescenta ainda que, para a primeira perspectiva, o ‘segundo' autor, o 'segundo’ momento da reflexão é sempre mais rico, mais completo ou, no mínimo, mais esclarecedor do que o primeiro. Para a segunda perspectiva, temos tanto um certo 'desprezo' pelo primeiro momento ou autor, expresso em certo 'tom de agressividade', próprio à 'revolução do pensamento', ou ainda um raciocínio mais 'sereno' de descontinuidade, 'desconsideração’ do primeiro autor ou momento.

\footnotetext{
2 Tradução: "Para Simone Delessale, Henry Weil e Charles Bally são os precursores da linguística enunciativa.[...] Referir-se a Benveniste quando se define a enunciação se torna, sabemos, uma prática corrente em linguística francesa. Nesse sentido, o artigo de Delesalle é representativo. É, além disso, fácil de constatar essa tendência tanto nos dicionários de língua quanto nos estudos linguísticos.” (Ono, 2007, p. 28)

3 Tradução nossa: “O menor dos riscos que ele corre não é aquele do anacronismo ou do presentismo, reduzindo o estudo histórico à pesquisa de 'precursores'?” (Colombat, Fournier e Puech, 2010, p. 240).

${ }^{4}$ Normand (2009b) apresenta, por sua vez, três paradigmas da relação entre Saussure e Benveniste: discurso de filiação, discurso da novidade e discurso da influência. Por ora, nos interessa observar não tanto as formas de leitura da relação entre linguistas mas discutir a relação 'história' e 'linguística'.
} 
No entanto, ainda que reconheça tal classificação do tratamento do 'passado da linguística', uma pontinha do ouvido psicanalítico não cessa de interrogar uma terceira percepção sobre a história da linguística e, sobretudo, sobre os historiadores da linguística. Seria o olhar retrospectivo sintoma de um olhar 'teleológico' - característica que a autora duramente refuta e critica à linguística - ou, ainda pior, "uma polícia dos conceitos'? (NORMAND, 2009a, p. 30-1). Atrelada a tal 'polícia dos conceitos' está a ideia de que um determinado autor 'inova' por que nele reconhecemos ‘um' termo que seria uma espécie de 'avatar da cultura de sua época'.

Entendemos, então, que o perigo de se fazer história da linguística é o de 'vender' a ideia de que um conceito ou autor atual é mais representativo de 'nossa' época do que qualquer outro, de 'outra' época. Tal perigo está contido tanto na abordagem de mudança na continuidade quanto de mudança na descontinuidade. Normand (2009a) nos coloca a armadilha, mas não nos ensina a desatá-la. Oferece-nos uma pista, por sua vez, ao deslocar o olhar da história da linguística para o historiador da linguística. Não mais a ordenada e tranquila organização das linguísticas em 'escolas', 'temas', 'objetos de pesquisa' e sim a inquieta relação das linguísticas em torno dos 'problemas' mais ou menos comuns pelo fazer do linguista.

Assim ela se expressa:

Avoir recours à la récurrence entraîne ainsi le recours à la méconnaissance: ils ne savent pas ce qui s'écrit par eux, parce que la distance n'est pas prise par rapport aux réseaux de pensée qui les gouvernent. Il faut être pris dans d'autres réseaux, non moins contraignants, pour voir ce qui n'était pas vu. « Lecture symptômale » certes, mais historique. La sympathie pour le passé, l'expérience de la très relative liberté de parole et un goût obstiné d'archiviste à la recherche des liaisons multiples d'un discours, doivent permettre d'éviter les pièges du jugement ${ }^{5}$. (NORMAND, 2009a, p. 33)

O recurso ao 'passado' para entender o 'presente' da teoria serve, portanto, como efeito de uma necessidade de evitar 'equívocos' de leitura ao reportar certas leituras a supostas ligações entre conceitos do presente texto e textos 'precursores'. Sintoma da liberdade e da isenção de leitura: sintoma ainda da necessidade do linguista de fazer a sua história. Fazer história da linguística é sempre, nesse sentido, re-criar-se, criando um novo 'narrador linguista'. O dizer do linguista e seus processos podem assim estar mais ou menos próximos ao romance histórico, realista ou outro estilo; em suma, o fazer do linguista não está dissociado de um fazer literário ${ }^{6}$.

Não é possível estabelecer a priori 'critérios de historicidade': resta-nos observar os processos individuais de cada linguista, compreender como cada um conta a história e, talvez, dizer como cada uma delas nos conduz.

\section{PERCURSOS DE LEITURA}

Neste item, apresentaremos os trabalhos de Ono (2007) e Delesalle (1986) na ordem como os conhecemos. Procuraremos flagrar os movimentos de 'contar a história da linguística' subjacentes ao trabalho dos autores. Em parte, tal trabalho foi senão realizado, sugerido no prefácio de Normand ao próprio trabalho de Ono (2007). A autora afirma que:

On pourrait craindre qu'elle ne tombe dans le piège d'une lecture téléologique un peu naïve; elle n'y échappe pas toujours quand elle commente ses analyses par des 'pas encore', 'dejá,' 'enfim...', mas elle enrichit heuressement cette démarche systematique par une constante interprétation [...] si ben que, joignant à la minute philologique le souci explicatif de l'histoire elle aboutit à cette 'empathie' dans

\footnotetext{
${ }_{5}^{5}$ Tradução nossa: "Tomar como recurso a recorrência desencadeia também o recurso ao mal-conhecimento: não se sabe o que se escreve por eles, por que a distância não é tomada por relação às redes de pensamentos que os governam. É necessário ser tomado em outras redes, não menos restritivas, mas ver o que não foi visto. "Leitura sintomática', certamente, mas histórica. A simpatia pelo passado, a experiência de relativa liberdade de fala e um gosto obstinado de arquivista à pesquisa de ligações múltiplas de um discurso, devem permitir evitar as armadilhas do julgamento." (Normand, 2009, p. 33)

${ }^{6}$ No Institut de Textes \&̊ Manuscrites Modernes (Item), Paris, há um grupo de pesquisa intitulado “Génétique et theories linguistiques ”coordenado por Irène Fenoglio, tem como objetivo compreender "a problématique du rapport entre élaboration théorique, formation de notions et concepts et production écrite sur manuscrits.” Veja-se mais detalhes em: http://www.item.ens.fr/index.php?id=13875. Os termos da relação entre o fazer do linguista e do fazer literário serão objeto de um próximo trabalho.
} 
laquelle Dilthey (et après lui Ricoeur) voyaient le propre de la compréhesion herméneutique. ${ }^{7}$ (NORMAND apud ONO, 2007, p. 232)

Observamos aí que Normand entrevê em alguns momentos uma compreensão senão puramente teleológica, ao menos, um afã hermenêutico em Ono (2007). Ainda que Ono (2007, p. 216) rejeite a metáfora do 'iceberg', percebemos que sua leitura, por vezes arqueológica, tenta dar conta de uma 'totalidade' do raciocínio benvenistiano.

Ainda assim, resta avaliar em que medida a limitação ou homogeneidade entrevista por Normand no método de leitura de Ono (2007) conduz um enredo asfixiante ou, pelo menos, ordenador de uma certa racionalidade sobre a língua. Para tal, utilizamos as noções de continuidadel descontinuidade em relação dicotômica ou em relação entremeada. Elaboramos as seguintes questões:

1) a distinção em 'aspectos da enunciação' reúne mas hierarquiza ou reúne mas observa descontinuidade?

2) o percurso cronológico de Ono (2007) observa um olhar puramente retrospectivo ou se percebem dúvidas ou bifurcações em alguns pontos?

Considerando os subtítulos do primeiro capítulo de Ono (2007)8, podemos perceber que há uma forte tentativa de 'cronologização' e 'homogeneidade' do pensamento benvenisteano. Neste capítulo, a autora propõe o estudo do termo 'enunciação' em textos de Benveniste, desde a década de 1940 até o texto 'O aparelho formal da enunciação’ (1970). Este artigo de Benveniste é, para Ono (2007), o texto em que a noção de 'enunciação' se encontra de forma mais complexa e mais ampla. A partir desse último texto, a autora propõe o estudo da 'enunciação' em cinco aspectos (aspecto vocal, aspecto individual, aspecto da conversão da língua em discurso, aspecto da referência, aspecto do estudo da dialogia). Percebe-se aí uma concepção de 'história da linguística' como o de uma 'acumulação linear e progressiva de saberes'.

Este movimento de cronologização, no entanto, é parcialmente revogado no segundo capítulo, intitulado “Trois notions associées: phrase, instance de discours, énonce performatif”, uma vez que noções nascidas em tempos diferentes são presentificadas.

De que natureza seria tal presentificação? Co-presença? Acreditamos que Ono (2007) observa 'mudança na continuidade' entre elas, como se pode ver em: “Tout en admettant comme lui que l'aspect prédicatif de la phrase influence le développement de la notion d'énonciation, nous ferons noter qu'en 1970, Benveniste ne l'évoque plus dans 'L'appareil'. La prédication est, en ce sens, un forme disparue de l'énonciation.”9 (ONO, 2007, p. 66). Nesse sentido, não se percebem dúvidas, bifurcações ou co-presença, e sim 'desaparecimentos' e 'silêncios'. Dessa forma, a dita ‘associação’ entre frase - que se caracteriza pelo aspecto predicativo - , instância de discurso e enunciado performativo deve ser observada com mais cuidado. Entre frase e instância de discurso, como vimos, Ono (2007) observa uma 'evolução', ou seja, algumas características da frase convivem na instância de discurso ainda que de forma subjacente (ou 'forme disparue'). Já entre instância de discurso e performativo, Ono (2007, p. 93) nos diz que: "L'énonciation est l' 'acte de produire un énoncé' (PLG 2, p. 80), tandis que l'acte performatif s'accomplit uniquement par sa nomination par l'énoncé. Il y a ici une discontinuité plutôt qu'une continuité des idées." ${ }^{10}$ Há, então, entre os três

\footnotetext{
7 Tradução nossa: "Poderíamos crer que ela não cai na armadilha de uma leitura teleológica um pouco ingênua, ela não escapa disso algumas vezes quando ela comenta que suas análises por "não ainda”, “já”, "enfim”, mas ela enriquece felizmente essa abordagem sistemática por uma constante interpretação [.. se bem que aderindo à minúcia filológica explicativa da história ela acabe nessa "empatia” na qual Dilthey (e depois dele Ricouer) viram como próprio da compreensão hermenêutica." (Normand apud Ono, 2007, p. 232).

${ }^{8}$ Os subtítulos são os seguintes: Le mot énonciation dans les textes, L’Appareil formel de l'énonciation; Symbolisme social dans les cultes grécoitaliques (1945): L'énonciation en tant qu'acte cérémoniel; La phrase nominal (1950): Apparition de l'emploi théorique d'énonciation; Tendances récentes en linguistique générale (1954): l'énonciation comme réalisation phonique; La nature des pronoms(1956): une énonciation chaque fois unique; De la subjectivité dans la language (1958a): énonciation et subjectivité; Les relations de temps dans le verbe français(1959): l'énonciation sur le plan narratif et dans la perspectiva dialogique; La philosophie analytique et le language (1963): l'énonciation est un acte; Structure de la langue et structure de la société (1968c): L'énonciation mise en rapport avc la société; Semiologie de la langue (1969): Le sémantique comme monde de l'énonciation; Synthèse.

9 Tradução nossa: “ Ao admitir como ele que o aspecto predicativo da frase influencia o desenvolvimento da noção de enunciação, nós fazemos notar que em 1970 Benveniste não o evoca mais em O aparelho formal. A predicação é, nesse sentido, uma forma desaparecida de enunciação.” (Ono, 2007, p. 66)

10 Tradução nossa: "A enunciação é o ato de produzir o enunciado (PLG 2:80), enquanto que o ato performativo, se realiza unicamente por sua nominação pelo enunciado. Há aqui discontinuidade mais do que uma continuidade de ideias.” (Ono, 2007, p.93)
} 
'associados' à enunciação uma forma de ligação diferente: a noção de enunciação se alarga ao longo da reflexão benvenisteana e cria limites.

A história da enunciação que nos conta Ono (2007), por ser uma história de 'dentro para fora', isto é, centrada na obra de autor, é a história da criação de uma tese, da fundação de um paradigma. Ono (2007) inaugura um novo olhar sobre a obra de Benveniste e, sua certeza e linearidade, tal olhar cria um efeito paradigmático de constância e consistências epistemológicas.

Apresentaremos, agora, o percurso da linguista Delesalle (1986). A autora busca, sem explicitar claramente na introdução do artigo, uma 'Histoire du mot énonciation'. Ela afirma encontrar a palavra enunciação em oito artigos que vão da antiguidade grega à idade clássica, passando pela tradição árabe, a Idade Média e a Renascença, chegando ao fim do século XIX e início do século XX com trabalhos como os de Paulhan, Durkheim e Bréal. Finalmente, Delasalle (1986, p. 8) afirma que o nascimento do domínio propriamente dito é analisado de Bally a Benveniste (p. 8). Segundo a autora, "cette naissance est à la fois bouleversante et ambiguë" 11 (p.8). A ambiguidade do 'nascimento da ideia da enunciação' que pode ser compreendida também como uma negação dessa ideia, é explicada na importante afirmação, a seguir, a qual pode nos servir de chave de leitura de todo o trabalho de Delesalle (1986):

On est donc passé d'une conception plurielle revêtant divers noms à un nom unique désignant une conception toujours plurielle mais d'une manière différente: dans le premier cas on repère à travers des domains divers ce que peut faire sense eu égard à la construction future, dans le second il s'agit de la dynamique proper à un domaine se développant à la frontière - ou à la disparition de la frontière - entre langue et parole. (DELESALLE, 1986, p. 9) ${ }^{12}$

A pluralidade inicial da palavra enunciação é da ordem de domínios de saberes diversos e a pluralidade atual, isto é, a partir de Bréal e Benveniste, é da ordem de um mesmo domínio de saberes. Percebemos aí uma mudança na descontinuidade (NORMAND, 2009a): trata-se de mais de uma mudança sistêmica do que uma mudança conceitual ou nocional propriamente dita. A ambiguidade do nascimento do termo 'enunciação' tal como o conhecemos hoje na linguística é reforçada pela autora quando afirma que:

Il n'y a donc pas là à mes yeux datation du mot dans son sens actuel, et je continuerai à situer le terminus ad quem de l'absence du sens linguistique dans les années 20, c'est a dire précisement au coeur de l'oeuvre de Charles Bally, mais avec des annonces de ce sens d'une parte, des prolongations des sens concurrents d'autre part, sur lesquelles on reviendra. ${ }^{13}$ (DELESALLE, 1986, p. 10)

Observamos aí que a ideia de concorrência e de prolongação impede uma plena noção de 'fundação' de um sentido puramente linguístico para enunciação. De qualquer forma, a autora não esclarece precisamente qual é a ligação do linguista Bally com outros domínios do saber, além da sugestão de uma 'concorrência' de sentidos.

Os domínios de saberes antes do 'nascimento da enunciação', são os seguintes: lógica, retórica e gramática. Delesalle (1986) situa o nascimento do termo no terreno da linguística com Bréal, mas não dá a ele a 'paternidade' de tal noção na época contemporânea, situando, então, a 'enunciação' de forma próxima tanto da gramática quanto da lógica e da retórica. Conclui a autora:

Des notions rhétoriques se sont donc glissés dans ce mot qui appartenait à la grammaire autant qu'à la logique. Weil d'une manière ponctuelle et précise, Bally en l'utilisant comme centre d'un système en devenir, guidaient déjà le mot vers le développement - éclatement qu'on lui connaît actuellement; le

\footnotetext{
${ }_{11}^{1}$ Tradução nossa: "Este nascimento é, ao mesmo tempo, perturbador e ambíguo.” (Delesalle, 1986, p. 8)

12 Tradução nossa: "Passamos portanto de uma concepção plural ... diversos nomes a um nome único designando uma concepção sempre plural mas de uma forma diferente: no primeiro caso identificiamos através de domínios diferentes, o que pode fazer sentido tendo em vista uma construção futura, no segundo caso, se trata da dinâmica própria de um domínio se desenvolvendo na fronteira - ou na desaparição da fronteira - entre língua e fala." (Delesalle, 1986, p. 9).

${ }_{13}$ Tradução nossa: "Não há portanto, a meu ver, datação da palavra no seu sentido atual, e eu continuarei a situar o termo aquém de sua existência linguística nos anos 20, isto é, precisamente no seio da obra de Charles Bally, mas com anúncios desse sentido de uma parte, prolongamentos de sentidos concorrentes de outra parte, sobre os quais voltaremos” (Delesalle, 1986, p. 10).
} 
vaganbodage des sens traditionnels du terme coexistant, on l'a vue, avec sa cristallisation linguistique et les problématiques qu'elle a suscitées. ${ }^{14}$ (DELESSALE, 1986, p. 20, grifos nossos)

Observamos aí uma persistência da ideia de 'concorrência' na atualidade: o sentido da palavra 'enunciação' na linguística concorre com sentidos, doravante ditos 'tradicionais', de outras áreas. No entanto, hoje, tal 'concorrência' tem visibilidade diferente. O termo 'enunciação' tem uma legitimidade social determinada pela circulação do termo na área denominada 'Linguística da Enunciação’.

Resta-nos nos perguntar: o que é mais determinante para a história da palavra enunciação em sua especificidade linguística: a noção de 'concorrência' ou a de 'descontinuidade'? A forma de escrita de Delesalle (1986) mais do que propriamente o que ela afirma nos revela que a descontinuidade contribui para a concorrência: o fato de a lógica, a retórica e a gramática terem usado o termo em sentidos diferentes possibilitou o 'meio criativo/polêmico' para que autores como Bréal e Benveniste constituíssem a teoria da enunciação.

Esta característica nos alerta sobre a importância da polêmica como método para gerar controvérsias e novas proposições teóricas para a ciência linguística. O atual estado de especialização da linguística - como se pode ler na obra Conversas com linguistas (2006) -, com seus 'objetos de pesquisa' cuidadosamente destacados, com seus 'temas' de preferência, pode indicar uma descontinuidade sem concorrência, fato que pode conduzir a uma crescente estirilização da própria criação teórica linguística.

Tanto Ono (2007) quanto Delesalle (1986) nos mostram caminhos de se escrever a história da linguística. É interessante nos questionarmos sobre a utilidade de um ou outro método para a linguística do século XXI. No próximo item, apresentamos uma breve reflexão sobre isso.

\section{HISTÓRIA DA LINGUÍSTICA: FANTASMA DA ONISCIÊNCIA?}

Benveniste, em Vista d'olhos sobre o desenvolvimento da linguística (1963), revela-se bastante otimista com o desenvolvimento da linguística, marcado pela multiplicação dos métodos, pelo interesse de outras áreas pelo conhecimento da linguagem e das línguas e pela crescente formalização do pensamento linguístico. Tal 'desenvolvimento' encontra-se em pleno fortalecimento no século XXI, ao menos no Brasil. Pouco tem se dito, no entanto, sobre essa história. A diversidade de métodos tem nos levado a um isolamento, a uma descontinuidade radical? A formalização tem nos levado a esquecer os problemas fundamentais?

Não faltam congressos congregando diversas áreas, sessões de comunicação, mesas temáticas. O interesse interdisciplinar é crescente. Haverá, contudo, um verdadeiro debate sobre os fundamentos de tais 'diálogos'? Nesse sentido, o trabalho de Delesalle (1986) nos parece mais proveitoso para o atual rumo que a linguística vem tomando no século XXI, uma vez que nele prepondera a consideração de diversas fontes em torno do mesmo tema. Não diríamos que Delesalle (1986) utiliza-se da abordagem problematológica (AUROUX, 1998). Nesse sentido, nossa hipótese não foi confirmada: nem Ono (2007) e nem Delesalle (1987) fizeram uso da abordagem problematológica. No entanto, a escrita dessa última autora, repleta de silêncios e descontinuidades nos faz perceber o desenho de um narrador senão plenamente polifônico - no sentido ducrotiano do termo ou, ao menos, não atrelado a um ponto de vista onisciente sobre a história da palavra enunciação. Ainda que Colombat, Fournier e Puech (2010) nos alertem para a necessidade de reconhecer e respeitar a diversidade de ideias sobre a linguagem e as línguas, entendemos que o trabalho de Ono (2007) tem um mérito: demonstrar a complexidade do texto 'O aparelho formal da enunciação', o qual é apresentado de forma muito simples por muitos outros autores. No mais, o trabalho de Delasalle (1986) ainda está por receber mais atenção por parte dos linguistas da enunciação, ao menos no Brasil.

Conclui-se, então, que a história da linguística não é um fantasma: no afã de se 'desenvolver', os linguistas esquecem, com algumas exceções, de rever seus métodos, seus conceitos, seu percurso, seus dizeres, sua escrita. Nunca é tarde para rever no presente ecos do passado, para observar descontinuidades, rupturas na

\footnotetext{
${ }_{14}$ Tradução nossa: "Noções retóricas são portanto desviadas dessa palavra que pertence à gramática tanto quanto à lógica. Weil, de uma maneira pontual e precisa, Bally utilizando como centro de um sistema a vir, guiando a palavra em direção ao seu desenvolvimento - ruptura que conhecemos atualmente; a errância de sentidos tradicionais do termo coexistem, vimos, com a cristalização linguística e as problemáticas que ela suscitou." (Delesalle, 1986, p. 20, grifos nossos).
} 
continuidade. A "história da linguística" pode - e deve ser - histórias da linguística. O narrador do linguista ainda está por surgir: senão, registre-se aqui tal urgência.

\section{REFERÊNCIAS}

AUROUX, S. A filosofia da linguagem. Campinas, SP: Editora da Unicamp, 1998.

BENVENISTE, E. Vista d'olhos sobre o desenvolvimento da linguística. In: Benveniste, E. Problemas de Linguística Geral I. Campinas, SP: Pontes, 1989, p. 19-33.

BRAIT, B. (Org.). Estudos Enunciativos no Brasil - Histórias e Perspectivas. Campinas: Pontes; FAPESP, 2001.

COLOMBAT, B.; FOURNIER, J.M.; PUECH, C. Histoire des idées sur le langage et les langues. Paris: Klincksieck, 2010.

DELESALLE, S. Introduction: histoire du mot enonciation. In: Tomo 8, fascículo 2, 1986, p. 3-22. Histoire, Epistemologie, Langage.

DUCROT, O. Esboço de uma teoria polifônica da enunciação. In: $O$ dizer e o dito. Campinas: Pontes, 1987.

FIORIN, J. L. Introdução à Linguística: objetos teóricos. São Paulo: Contexto, 2005.

FLORES, V.; TEIXEIRA, M. Introdução à linguística da enunciação. São Paulo: Contexto, 2005.

FLORES, V.; BARBISAN, L. Sobre Saussure, Benveniste e outras histórias da linguistica. In: NORMAND, C. Convite à linguística. São Paulo: Contexto, 2009. p. 7-20.

MARTIN, R. Para entender a linguística. São Paulo: Parábola, 2003.

MUSSALIM, F.; BENTES, A. C. (Orgs.). Introdução à lingüística: fundamentos epistemológicos, v.3. 1. ed. São Paulo: Cortez, 2004. v. 3.

NORMAND, C. Coment faire l'histoire de la linguistique? Cahiers de l'ILSL, n. 26, p. 21-36, 2009a.

NORMAND, C. Saussure-Benveniste. In: Convite à linguística. São Paulo: Contexto, 2009b. p. 197204.

ONO, A. La notion de enunciation chez Émile Benveniste. Paris: Limoges, 2007.

Recebido em 26/07/2013. Aprovado em 02/02/2014. 